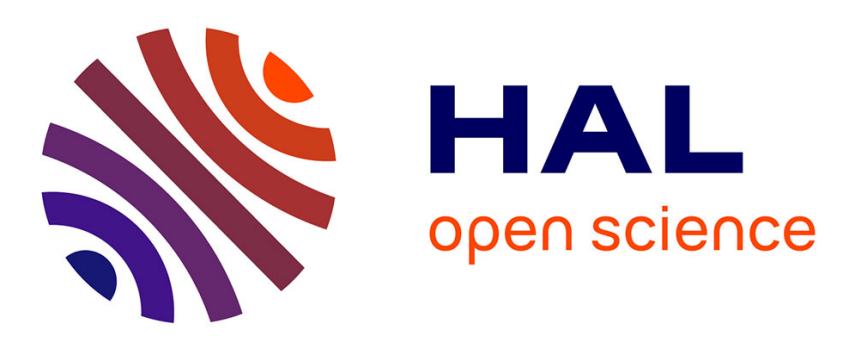

\title{
Phonological mediation in visual masked priming: Evidence from phonotactic repair
}

Pierre Hallé, Alberto Dominguez, Fernando Cuetos, Juan Seguí

\section{To cite this version:}

Pierre Hallé, Alberto Dominguez, Fernando Cuetos, Juan Seguí. Phonological mediation in visual masked priming: Evidence from phonotactic repair. Journal of Experimental Psychology: Human Perception and Performance, 2008, 34 (1), pp.177-192. halshs-00683856

\section{HAL Id: halshs-00683856 \\ https://shs.hal.science/halshs-00683856}

Submitted on 30 Mar 2012

HAL is a multi-disciplinary open access archive for the deposit and dissemination of scientific research documents, whether they are published or not. The documents may come from teaching and research institutions in France or abroad, or from public or private research centers.
L'archive ouverte pluridisciplinaire HAL, est destinée au dépôt et à la diffusion de documents scientifiques de niveau recherche, publiés ou non, émanant des établissements d'enseignement et de recherche français ou étrangers, des laboratoires publics ou privés. 
Phonological mediation in visual masked priming: Evidence from phonotactic repair

\author{
Pierre A. Hallé, ${ }^{\mathrm{a}, \mathrm{de}}$ Alberto Dominguez, ${ }^{\mathrm{b}}$ Fernando Cuetos, ${ }^{\mathrm{c}}$ and Juan Segui ${ }^{\mathrm{d}}$ \\ ${ }^{a}$ Laboratoire de Phonétique et Phonologie (CNRS-Paris 3), \\ ${ }^{\mathrm{b}}$ Universidad de La Laguna, ${ }^{\mathrm{c}}$ Universidad de Oviedo, \\ ${ }^{\mathrm{d}}$ Laboratoire de Psychologie et Neurosciences Cognitives (CNRS-Paris 5), \\ ${ }^{\mathrm{e}}$ Haskins Laboratories
}

Running title: Phonological mediation via phonotactic repair

Address for correspondence:

Pierre A. Hallé

Laboratoire de Phonétique et Phonologie,

19 rue des Bernardins, 75005 Paris (France)

e-mail: pierre.halle@univ-paris5.fr 


\begin{abstract}
In a series of four experiments, it is shown that phonological repair mechanisms, known to operate in the auditory modality, are directly translated in the visual modality. This holds with the provision that printed stimuli are presented for a very brief duration and that the effect of phonological repair is tested after a delay of some $100 \mathrm{~ms}$ has elapsed after that presentation. The case of phonological repair chosen to exemplify the parallelism between print and speech is the prosthesis of /e/ in utterances beginning with /s/ followed by a consonant in Spanish. Native speakers of Spanish hear a prothetic/e/ in auditorily presented pseudowords such as special (/spe日jal/, derived from “especial”) as well as stuto (/stuto/, derived from "astuto"). It is shown here that they also hear that same vowel /e/ when presented with the printed pseudowords "special" and "stuto." This finding of a "phonological repair effect" in print bears implications on the issue of phonological activation from print, as well as on the prelexical locus and mandatory nature of phonological repair mechanisms in general.
\end{abstract}

Keywords: Visual masked priming, letter-to-sound conversion, phonological code, phonological repair, Spanish, vowel prosthesis 


\section{Introduction}

Many studies using visual masked priming procedures, for target word identification or lexical decision, have shown that printed words and pseudowords activate a phonological as well as an orthographic code, and that such activation obtains even for primes exposed so briefly that they cannot be processed consciously. It obtains in forward priming experiments (prime before target) (Ferrand \& Grainger, 1993; Frost, 1994, 1998; Grainger \& Ferrand, 1994; Lesch \& Pollatsek, 1993, 1998; Lukatela, Frost, \& Turvey, 1999; Lukatela \& Turvey, 1994; Perfetti \& Bell, 1991) as well as in backward priming (target before prime) (Berent \& Perfetti, 1995; Perfetti, Bell, \& Delaney, 1988; Tan \& Perfetti, 1999). Phonological code activation from brief visual exposure seems to be solidly established not only for alphabetic writing systems, whether deep or shallow, but for logographic writing systems as well (Guo, Peng, \& Liu, 2005; Perfetti \& Tan, 1998; Tan, Hoosain, \& Peng, 1995). Another line of evidence for phonological code activation from presumably subliminal print is provided by studies of letter detection in pseudowords or in words presented as briefly as $30 \mathrm{~ms}$ with a strong post-stimulus mask. For instance, Ziegler and Jacobs have demonstrated that subjects falsely detect 'i' in "brane," homophonous with "brain," and, symmetrically, miss 'i' in "crain," homophonous with "crane" (Ziegler \& Jacobs, 1995; Ziegler, Van Orden, \& Jacobs, 1997). In a similar vein, Chéreau, Hallé, and Segui (in revision) found a bias toward falsely detecting ' $\mathrm{z}$ ' and missing ' $\mathrm{s}$ ' in "asile" (/azil/), that is, toward "seeing" the letter that matches best with the word's phonological code. Importantly, subliminal primes and/or targets were used in all the situations mentioned so far. Therefore, the processes whereby a phonological code was activated were most likely automatic, in the sense of out of conscious control.

In the present study, we explore a particular yet difficult to ignore aspect of the phonological code: "repairs" applying to inputs that are phonologically not permissible in the 
subjects' native language. ${ }^{1}$ Are repairs incorporated to the phonological code activated from print or do they apply only to speech and, perhaps, at some conscious level of processing?

In auditory presentation, stimuli that are phonotactically impermissible in a given language may be perceptually repaired so that they become permissible sequences of sounds. Such repair processes can be viewed as resulting from the "perceptual assimilation" of nonnative sequences into native sequences (Best, 1995). One example is the case of the epenthetic vowel /u/ heard by Japanese listeners within clusters such as [bz] (Dupoux, Kakehi, Hirose, Pallier, \& Mehler, 1999). An "illusory" epenthetic /u/ is heard in [ebzo] by Japanese listeners: the illegal sequence [ebzo] is thereby repaired into /ebuzo/, complying with Japanese phonotactic constraints. This repair is not induced by lexical feedback as is shown by the fact that [mikdo] is repaired into the nonword /mikudo/ rather than the word /mikado/ (Dupoux, Pallier, Kakehi, \& Mehler, 2001). Another example is the case of the dental-to-velar shift for utterance-initial */tl/ or */dl/ clusters, heard as /gl/ or /kl/ by Frenchor English-speaking listeners (Hallé, Segui, Frauenfelder, \& Meunier, 1998). Here again, the repair process seems to be prelexical (Hallé, \& Best, 2007). However, the prelexical locus of these processes is still a matter of controversy. The TRACE model, for instance, would explain the $/ \mathrm{t} \mathrm{l} / \rightarrow / \mathrm{kl} /$ perceptual shift in terms of lexical feedback (McClelland \& Elman, 1986), just like it does for the categorical boundary shift in $/ \mathrm{r} /-/ 1 /$ continua preceded by $/ \mathrm{t} /$ that reflects a bias towards legal /tr/ rather than illegal */tl/ (Massaro and Cohen, 1983). In contrast, the MERGE model claims that these class of phenomena are driven by bottom-up processing only, at a prelexical level (Norris, McQueen, \& Cutler, 2000).

In alphabetic writing systems, grapheme-to-phoneme mappings are largely predictable (especially when context dependence is taken into account), although various systems may exhibit variously deep or shallow orthographies, or various degrees of graphic-phonologic consistency. One issue raised in the present study is, therefore, whether alterations of letter 
strings that are parallel to alterations of phoneme strings can give rise to repair mechanisms parallel to those observed directly in the auditory modality. For example, would the printed sequence "tla" activate the phonological code $/ \mathrm{kla} /$, just like the spoken sequence */tla/ does? It would require that letter-to-sound conversion retain the order and position of printed letters. Put another way, the processing of letter sequences should retain, at some level of analysis, positional information.

The similarity in processing speech and print would suggest that letter strings are directly translated into their phonemic counterparts in a one-to-one manner, whether they form permissible strings or not. Second, it would indicate that phonological repairs, which might be viewed as an external, decisional component in the construction of the perceived phonemic code, rather are built-in within the processes that convert a phonemic input into a phonemic percept. Finally, because the phonological effects observed in visual masked priming arise very early in the time course of processing and presumably have a prelexical locus (for recent evidence, see Lukatela, Eaton, Lee, Carello, \& Turvey, 2002), phonological repair from print would provide evidence for the automatic nature and the prelexical locus of phonological repair in general.

An interesting case of phonological repair is illustrated by Spanish speakers who pronounce esport for sport, esmile for smile, etc., even after a long stay in an Englishspeaking country. This anecdotal yet widely shared observation is substantiated by the systematic prosthesis of /e/ in the loanwords introduced in Spanish from foreign words beginning with /s/+consonant (Harris, 1983). The addition of a prothetic /e/ in loanwords, as well as in the widely observed mispronunciations produced by Spanish speakers, is motivated by the phonotactic ban in Spanish on /s/+consonant clusters in word-initial position. ${ }^{2}$ The /e/ vowel prosthesis can be viewed as a case of phonological repair at the language output level. 
However, we are concerned here with the input rather than the output level: Do Spanish speakers/listeners hear a prothetic/e/ in foreign words such as sport? There is indeed some empirical evidence for the perception of a prothetic /e/ by Spanish-speaking listeners, which parallels the perception of an epenthetic / $\mathrm{u} /$ by Japanese listeners. Theodore and Schmidt (2003) found that native speakers of Spanish report hearing an utterance-initial /e/ in all the stimuli of continua such as [stib]-[estib], regardless of the manipulated duration of the initial vowel (from 0 to $\sim 100 \mathrm{~ms}$ ). In contrast, English-speaking listeners do not hear the /e/ if it is shorter than 20-30 ms. This is very similar to Dupoux et al.'s (1999) finding of Japanese listeners hearing an epenthetic /u/ in continua such as [ebzo]-[ebuzo], whatever the actual duration of [u]. Hallé and Segui (2003) used either pseudowords such as special derived from especial ('special') and stuto derived from astuto ('shrewd'), or nonwords such as squida in a transcription task; they found that native speakers of Spanish tend to "restore" the missing vowel as /e/, even in the case of stuto or squida, which are not restored into words by this addition: the "*s $C \rightarrow e s C$ repair" thus seems prelexical. As we will see next, that both special and stuto are repaired with/e/, yielding a word (especial) and a nonword (estuto), respectively, is at the core of the design of the present study.

Let us return to the visual masked priming paradigm. As we noted earlier, the phonological and orthographic codes are closely related in languages with an alphabetic writing system. This is especially true for Spanish, in which grapheme-to-phoneme relationships are transparent and regular. Following the hypothesis that letter strings are directly translated into their phonemic string counterparts, permissible or not, we may surmise that word-initial "st" activate the phonological code /est/, just like the phonemic sequence */st/ would, by virtue of the ${ }_{s} C \rightarrow e s C$ repair. By this view, a prime such as "special" should activate the phonological form especial (shorthand for /espe $\theta \mathrm{jal} /$ ) together with the graphic form "especial," by virtue of orthographic overlap; both codes would hence concur to pre- 
activate the word "especial" and facilitate its recognition. In contrast, a prime such as "stuto" should activate the phonological form estuto in addition to the graphic form "astuto"; in this case, the two codes are conflicting and a lesser pre-activation of the word "astuto" is to be expected, as compared to the pre-activation of "especial" by "special." Therefore, especially if the task on the target stimulus is lexical decision, the outcome of the ${ }_{s} C \rightarrow e s C$ repair clearly favors the target in "special"-"especial" over that in "stuto"-“astuto." In other words, less priming should be found for "stuto"-"astuto" than for "special"-"especial," since the repair would result in a nonword in the former case ("estuto": a counter-productive repair) but in a word in the latter case ("especial": a productive repair). ${ }^{3}$ Such differential priming effects would reflect the operation of the ${ }_{s} C \rightarrow e s C$ repair as an integral part of phonological activation from print. In order to test for the operation of this repair, it is thus crucial to compare priming effects for "special"-“especial” and "stuto"-“astuto." Classic "net" priming effects (unrelated - related RT differences) could be compared, but the comparison would be problematic: it is difficult to ensure that ideally neutral primes be unrelated to targets to the same extent for "especial" and "astuto." This problem is readily avoided by gauging priming effects with reference to the full repetition condition, which always ensure maximum redundancy and thus conceivably yields the largest possible priming effect whatever the repeated word (with, perhaps, some modulation of the effect by item-specific properties such as lexical frequency, competition, word-length, etc.). In the experiments reported in this study, we will therefore always use the full repetition condition as a reference baseline to compare priming effects in partial repetition conditions.

Because phonological effects have been found in forward masked priming for prime exposure durations as short as 40 ms (e.g., Kim \& Davis, 2002; Lukatela \& Turvey, 1994), we begin with briefly exposed primes immediately followed by a target, on which participants 
perform a lexical decision. We then further explore forward priming situations with longer prime-to-target delays (SOA) while maintaining constant prime exposure duration.

\section{Experiment 1}

In this experiment, we look at the possible consequences of a ${ }_{s} C \rightarrow e s C$ phonological repair in comparing "especial" versus "astuto" targets for full versus partial (initial vowel suppressed) repetition forward priming, with briefly exposed primes immediately followed by target. The phonological repair hypothesis predicts an interaction between target type and priming condition, with a larger decrease in priming for "stuto" than for "special" primes with respect to the full repetition priming condition.

\section{Method}

Participants. Thirty students, native speakers of Spanish, enrolled in the introductory program of Psychology at the University of La Laguna, participated in this experiment for course credit. They reported no deficit in vision, audition, or language use.

Stimuli and design. Forty-eight test target words beginning with $\mathrm{VsC}$ were used. V was /e/ for half of the target words (e.g., "especial," “estación”) and was different from /e/ for the other half (e.g., "aspecto," "astuto"). Words beginning with a "silent" 'h' were not included in the set of target words. In Spanish, there are relatively few $\mathrm{VsC}$ - word types with $\mathrm{V} \neq / \mathrm{e} /$ compared to those with $\mathrm{V}=/ \mathrm{e} /(401$ vs. 2070 word types according to Alameda and Cuetos' [1995] frequency dictionary). Therefore, no attempt was made at using an equal number of each of the vowels other than /e/ (/a, i, u, o/), or of each of the /p, t, k/ consonants as the right context for $/ \mathrm{s} /$ : within the $\mathrm{V} \neq / \mathrm{e} / \mathrm{VsC}$ - words, there were a majority of $/ \mathrm{a} / \mathrm{s}$ for $\mathrm{V}$ (19 out of 24; for convenience, we thus call "asC-words" the $\mathrm{VsC}$ - words with $\mathrm{V} \neq / \mathrm{e} /$ ), and a majority 
of $/ \mathrm{t} / \mathrm{s}$ for $\mathrm{C}(15 / \mathrm{t} / \mathrm{s}, 6 / \mathrm{p} / \mathrm{s}$, and $/ 3 / \mathrm{k} / \mathrm{s})$. The proportions of $/ \mathrm{p}, \mathrm{t}, \mathrm{k} /$ in the esC- words were matched to those in the asC- words; asC- and esC- words were also matched in terms of number of letters ( 8.5 vs. 8.2 letters, n.s.), number of syllables (3.8 vs. 3.7, n.s.), and frequency of occurrence (13.1 vs. 13.2 occurrences per million according to the Alameda and Cuetos' [1995] frequency dictionary; the corresponding log frequencies both were 0.57). The 48 test targets words were combined with either an identical prime (full repetition) or with an "sC-" prime, obtained by suppressing the word-initial vowel letter (partial repetition). The 96 prime-target pairs so obtained were presented in lower-upper case letters (e.g., estación-ESTACIÓN, astuto-ASTUTO). The prime-target pairs were split into two lists so that priming condition (partial vs. full repetition) and target type (/e/- vs. non-/e/- target words) were counterbalanced across the two lists. Each list thus contained 12 pairs of each of the four prime-target types. The number of letters and of syllables, as well as the frequencies of occurrence were balanced at best between the two lists (see Appendix A). Half of the participants were assigned to one list, and the other half to the other list, so that each participant was presented with all of the 48 test targets but only once. Each participant also received 30 filler prime-target pairs with word targets (mean length 7.9 letters, mean frequency 32.2); the filler word targets began with $\mathrm{CV}$; half of them were associated with an identical prime and the other half with a pseudo-word obtained in suppressing the first letter. Finally, 60 prime-target pairs with nonword prime and target were added. Twenty of them consisted of an $\mathrm{sC}$ - prime followed by a $\mathrm{VsC}$ - nonword. This design was intended to avoid a strategic bias toward 'word' responses based on the sole perception of the first letters of the prime and/or the target. To summarize, each participant was presented with 48 test prime-target pairs (word targets), 30 filler pairs with a word target, and 60 filler pairs with a nonword target. A set of nine practice prime-target pairs was also constructed, among which three pairs had a nonword as target. 
Procedure. Each trial consisted in the following events: first, a sequence of '\#' signs, centered on the screen, appeared for $500 \mathrm{~ms}$; it was followed by the prime, presented in lower-case letters for $44 \mathrm{~ms}$, and immediately followed by the target presented in upper-case letters, which remained displayed until the subject pressed a response key, within the limits of a time-out duration fixed to $2000 \mathrm{~ms}$. Primes and targets as well as the hash marks were displayed in white characters (24 point Courier New) on a black background. Participants were instructed to respond for each trial, as quickly and accurately as possible, by pressing one of the two response buttons assigned to the 'word' and 'nonword' responses, using their better skilled hand to produce the 'word' response. The experiment was run using the DMDX software (Forster \& Forster, 2003) with a game pad as response input device, which ensured 1 ms response time precision.

Results and discussion

Table 1 summarizes the raw results for the four categories of test stimuli (2 target types $\times 2$ priming conditions). We call "alteration effect" the RT difference between the partial and full repetition priming conditions: a positive difference would reflect the presumably detrimental effect of suppressing the initial vowel in the prime, hence indeed, an alteration effect. In this experiment as well as in the subsequent ones, all the responses given before the 2-second time-out had elapsed (hence, with RT $<2000 \mathrm{~ms}$ ) were retained; responses given after time-out were treated as missing data $(3.1 \%$ of the data). Nine test target words (five from the "astuto" category and four from the "especial" category) induced more than $40 \%$ errors across full and partial repetition conditions and were discarded from the analyses. Analyses of variance were performed on the RT and error data, with the factors Target type (asC- vs. esC-) and Priming condition (full vs. partial repetition). Priming 
condition and Target type had no significant effect on the RT data. Target type was significant for the error data, $p \mathrm{~s}<.01$, with more errors for "especial" than "astuto" targets. No other factor or interaction was significant. To sum up, there was no significant decrease in priming between the full and partial repetition conditions, for both the "especial" and the "oscuro" target types, and no interaction between Target type and Priming condition. Hence, we found no evidence for an effect of a ${ }_{s} C \rightarrow e s C$ phonological repair.

\section{- Table 1 about here -}

Because there was a substantial range of variation in the materials we used with respect to target word length or frequency, we looked at the possible correlations between their characteristics and alteration effects. Although no alteration effects were observed overall, they perhaps would obtain only for short, or only for infrequent target words. For instance, the suppression of one letter in the prime could conceivably give way to larger alteration effects for short than for long targets because the alteration is proportionally larger. Thus, a negative correlation between target length and alteration effect could obtain. Target length correlated positively with RT for all priming conditions and target types $(p s<.005)$, consistent with the literature on visual lexical decision (e.g., O’Regan \& Jacobs, 1992). ${ }^{4}$ But, crucially, target length did not correlate with the RT difference between partial and full repetition, that is, with the alteration effect. Likewise, target word frequency tended to correlate negatively with RT but did not correlate with the alteration effect.

One aspect of the data deserves further inspection. Participants were quite slow overall and the range of speed variation across participants was quite large. It is conceivable, then, that a differential alteration effect be found for a subset of participants, based on overall speed. For example, fast subjects could project a phonological code more quickly than the others, and thus could show an alteration effect. The data were therefore split into "fast" and "slow" subjects. For the 15 fast subjects, neither Target type nor Target type x Priming 
condition interaction were significant, $F \mathrm{~s}<1$, hence no trace of a phonological repair effect was found. Indeed, although the fast subjects tended to produce longer RTs in the partial than in the full repetition priming condition, this trend was not significant $(p s>.2)$ and was numerically equivalent for the "astuto" and "especial" target types ("astuto": 881 vs. $849 \mathrm{~ms}$; “especial”: 874 vs. $831 \mathrm{~ms}$ ). Likewise, for the 15 slow subjects, no significant main effect nor Target type $x$ Priming condition interaction was found. In other words, both the slow and fast subjects data are inconsistent with the prediction of a phonological repair mechanism since the alteration effect is no larger for the "astuto" than for the "especial" targets, as repeatedly shown by the absence of a Target type $x$ Priming condition interaction predicted by the ${ }_{s} C \rightarrow e s C$ phonological repair hypothesis.

That no trace of a phonological repair mechanism was observed in Experiment 1 does not necessarily mean that no such mechanism is ever at work. It may be the case that, in the experimental setting we used, the predicted phonological effect is superseded by the effect of a massive orthographic overlap. In other words, a $44 \mathrm{~ms} \mathrm{SOA} \mathrm{might} \mathrm{be} \mathrm{too} \mathrm{short} \mathrm{for} \mathrm{a}$ phonological effect to emerge when challenged by a contemporaneous orthographic overlap effect. Indeed, previous research has pointed to differences in time course and/or degree of activation between the graphemic and phonological codes (Ferrand \& Grainger, 1993, 1994; Perfetti \& Bell, 1991; Rayner, Sereno, Lesch, \& Pollatsek, 1995; Tan \& Perfetti, 1999). Phonological priming is generally observed to arise quite early but as either weaker or later than orthographic priming. For instance, Ferrand and Grainger's (1993) study showed that, in a visual masked priming situation comparable to that of the present study, orthographic code was clearly dominant over phonological code for SOAs in the 33-50 ms range. The situation was reversed for longer SOAs: phonological code became dominant, peaking at $67 \mathrm{~ms}$ SOA.

In the following experiment, we use a longer SOA than $44 \mathrm{~ms}$, since $44 \mathrm{~ms}$ may fall in the range of a clear dominance of orthographic over phonological code. If phonological 
activation unfolds in time later than orthographic activation, the same priming stimulation as used thus far could generate phonological activation at a later point in time than was tested in Experiment 1; by then, the differential effects of the ${ }_{s} C \rightarrow e s C$ repair for "especial" versus “astuto" targets might emerge.

\section{Experiment 2}

In Experiment 2, the same forward priming procedure as in Experiment 1 was used, with prime exposure duration unchanged, but with a longer SOA obtained by inserting a hash mark post-mask between prime and target. This difference in stimulus presentation, necessary to increase SOA while preserving prime duration, may logically also increase prime visibility because a post-mask cannot radically "freeze" perceptual stimulation. It is thus important to know whether primes become consciously visible in the post-mask condition. Experiment 2 addressed this issue in using a simple test of prime visibility: an independent group of subjects were asked to discriminate prime and target in the same series of trials presented for lexical decision. This "visibility" test is reported first. We then proceed to the primed lexical decision test, similar to that of Experiment 1. Visibility is estimated from prime-target discrimination performance because discrimination directly reflects the putative capacity of listeners to notice redundancy vs. discrepancy between prime and target. Primetarget redundancy may be viewed as the driving source of priming effects. It is thus of interest to know whether it is consciously perceived. We will consider that primes are not consciously perceivable, if prime-target discrimination performance is not above chance level.

\section{Prime visibility}

Method

Participants. Twenty-six Spanish students from the same population as that used in 
Experiment 1, participated in this test for course credit. All of them reported normal vision, audition, and language abilities.

Stimuli and design. The same 48 critical asC- and esC- target words as in Experiment 1 were used, combined again with either an identical prime or an "sC-" prime obtained by deleting the word-initial vowel letter. Another 48 filler target words were added, combined with either an identical prime or a totally different word with roughly the same number of letters: for instance, the "recreo" target was combined with either "recreo" or "cantar" primes. The filler target words were matched with the other targets in terms of length (8.3 letters in average, ranging from 6 to 13 letters) and lexical frequency (12.2 o.p.m.). They are listed in Appendix B with their associated prime in the different-prime condition. The 192 prime-target pairs were split into two lists of 96 pairs so that priming condition (same vs. different) and target type (esC- vs. asC- words for the test targets) were counterbalanced across the two lists. Each participant, randomly assigned to one of these two lists, was thus presented a total of 96 trials: 48 test trials with an asC- or esC- target preceded by an identical or an $\mathrm{sC}$ - prime, and 48 filler trials with a filler target preceded by itself or by a different word. A set of nine practice prime-target pairs was presented before the 96 experimental trials.

Procedure. The presentation of the stimuli differed from that in Experiment 1 in that a $44 \mathrm{~ms}$ post-mask, a sequence of hash marks, was presented between prime and target. Participants were explicitly informed that, in each trial, the target was preceded by a sequence of hash marks, which was itself preceded by a printed sequence of letters. They were also informed that prime and target were identical (regardless of letter-case) exactly $50 \%$ of the time, and different the rest of the time. For each trial, they had to judge whether prime and target were identical or not. They were instructed to respond for each trial by pressing one of the two 
buttons of the input device used in Experiment 1, assigned in this experiment to the "same" and "different" responses, using their better skilled hand to produce the "different" response. Because greater difficulty in this task than in visual lexical decision was expected, subjects were given $3 \mathrm{~s}$ to respond instead of $2 \mathrm{~s}$ in Experiment 1.

Results and discussion

There were a total of 35 trials with a missing response (1.4\%), 19 for the "different" trials (target differed from the prime) and 16 for the "same" trials (identical prime and target). Responses were scored as hits when a prime-target difference was detected, as is usual in discrimination procedures. For the test and filler trials pooled, the overall percentage of correct responses (hits and correct rejections), was 50.0\%, while the percentage of incorrect responses (misses and false alarms) was $48.6 \%$; this difference was not significant, $|t 1(25)|<$ $1 ;|t 2(95)|<1$. The results are detailed by trial type in Table 2 . We first analyzed the test trials data, with Target type ("astuto" vs. "especial”) as main factor, and Response type (“correct" vs. incorrect") as a repeated measure. Target type was far from significance, $F \mathbf{s}<$ 1, showing that "astuto" and "especial" behaved similarly. Response type was not significant either, $F 1(1,25)<1 ; F 2(1,46)=2.14, p=.15$. That is, correct response rate was not greater than incorrect response rate. We also ran a signal detection analysis on the subject data for test trials. The classic index of discrimination, d', did not differ from 0 (average d': 0.091), $t(25)=0.41, p=.68 ; \beta$ was significantly above $1(1.24), t(25)=2.73, p<.05$, indicating a slight bias toward "same" responses for the test trials. Of course, the signal detection analysis we run should be considered with caution because it is based on only 48 observations per subject. However, it is in good agreement with the absence of a significant advantage for correct over incorrect responses: subjects showed no sign of discriminating "stuto" from "astuto" or "special" from "especial." Filler trials tended to induce slightly less correct 
responses than test trials (48.2\% vs. $51.8 \%)$ but this difference did not reach significance, $|t 1|$ $<1 ; t 2(47)=1.19, p=.24 .^{5}$ Therefore, for both test and filler trials, subjects' performance was not above chance level. We thus conclude to the lack of prime visibility in the situation used: 44 ms primes immediately followed by a $44 \mathrm{~ms}$ hash mark post-mask and then a target.

\section{— Table 2 about here -}

\section{Primed lexical decision}

Method

Participants. Forty-three Spanish students from the same population as in Experiment 1 participated in this experiment for course credit. They did not participate in the preceding experiment and reported no deficit in vision, audition, or language use. Nine subjects were extremely slow (their average RT across conditions exceeded $1000 \mathrm{~ms}$ ) and their data were not retained. This left 34 subjects with a grand average RT of $788 \mathrm{~ms}$.

Stimuli and design. Identical to that used in Experiment 1.

Procedure. The procedure differed from that used in Experiment 1 in that the prime was followed by a 44 ms post-mask (a sequence of '\#' signs). In this way, the prime-to-target SOA was $88 \mathrm{~ms}$, while the prime exposure duration was the same as in Experiment 1. This is of course only an effort at maintaining constant the perceptual trace of the prime stimulation. The rudimentary although widely used hash mark post-mask presumably leaves a stronger perceptual trace at target onset in Experiment 2 than in Experiment 1 (cf. Smithson \& Mollon, 2006). Yet, the visibility test just reported has suggested that primes are not much visible, if at all, in the present stimulus presentation conditions. We may thus safely assume that the main difference between the lexical decision tests in Experiments 1 and 2 lies in the longer SOA in Experiment 2, which allows a $44 \mathrm{~ms}$ increase in processing time. 
Results and discussion

The results are summarized in Table 3. The missing data amounted to $0.25 \%$ of the data. Twelve test target words (six from each of the "astuto" and "especial" categories) induced more than $40 \%$ errors and were thus discarded from the analyses. Analyses of variance were performed as in Experiment 1 on the RT and error data, with the same factors Target type and Priming condition. For the RT data, Target type was not significant $(F \mathrm{~s}<1)$ but Priming condition was, $F 1(1,33)=5.35, p<.05, \eta_{\mathrm{p}}^{2}=0.120 ; F 2(1,34)=4.63, p<.05, \eta_{\mathrm{p}}^{2}$ $=0.139$, reflecting longer RTs overall in the partial than in the full repetition condition $(805>$ $772 \mathrm{~ms}$ ). The Target $x$ Priming interaction was not significant. However, Priming type significantly affected "astuto" targets, with longer RTs in the partial than in the full repetition condition, $t 1(33)=2.70, p<.05 ; t 2(17)=2.08, p=.052$ (marginal), but not "especial" targets. As for the error data, the effect of Target type was significant in the subjects analysis, $F 1(1$, $33)=9.11, p<.005, \eta_{\mathrm{p}}^{2}=0.216$, but not in the items analysis, $F 2(1,34)=1.31, p=.26$, reflecting less errors overall for "astuto" than for "especial" targets $(8.9 \%<12.9 \%)$. But Priming condition had no effect and did not interact with Target type $\left(F_{\mathrm{S}}<1\right)$.

— Table 3 about here -

As in Experiment 1, we looked at the correlations between the target length or frequency and the items data. Target length correlated positively with RT, whatever the priming condition or the target type $(p s<.001)$, but not with the alteration effect. Target word frequency tended to correlate negatively with RT but not with the alteration effect. We also looked at the subjects data according to overall response speed: the alteration effect did not correlate with subject-wise average $\mathrm{RT}$, for either asC- or esC- words.

The results do not show a significant interaction between Target type and Priming condition, as the operation of a ${ }_{s} C \rightarrow e s C$ phonological repair predicts. However, the pattern 
of results in Experiment 2, in which an alteration effect was found for "astuto" targets, strikingly differs from that in Experiment 1, in which no trace of an alteration effect was found for either "especial" or "astuto" targets.

As a straightforward account for this difference, we propose that primes were not processed beyond the orthographic level in Experiment 1, whereas they began to be coded phonologically in Experiment 2. In Experiment 1, orthographic overlap was sufficient in the partial repetition condition to produce nearly as much priming as in the full repetition condition. In Experiment 2, phonological discrepancy in the partial repetition condition affected priming: there was less priming for partial than full repetition. That partial repetition prime-target discrepancy has more sizeable consequences at the phonological than orthographic level should not be surprising: deleting the initial vowel is deleting the initial syllable, and results in a phonemic sequence which is not permissible in Spanish.

The difference between "astuto" and "especial" in the magnitude of the alteration effect, although not supported by a significant interaction Target type $\mathrm{x}$ Priming condition interaction, also suggests an emerging advantage in terms of phonological redundancy for "special"-“especial" over "stuto"-“astuto," which is congruent with the *sC $\rightarrow e s C$ phonological repair. To sum up, it seems that primes were processed less superficially in Experiment 2 than in Experiment 1, conceivably because (1) more processing time was available (SOA was increased by $44 \mathrm{~ms}$ ) and (2) the perceptual trace of primes may be somewhat stronger in Experiment 2, due to the noted difficulty of displacing or overwriting iconic memory (Smithson \& Mollon, 2006).

In Experiment 3, we use an even longer SOA than in Experiment 2, while keeping constant prime and post-mask duration. If this longer SOA is sufficient for the phonological code of the prime to build and cohere, and if indeed "special" leads to especial and "stuto" to * estuto, then we should observe an interaction between Priming condition and Target type. 


\section{Experiment 3}

In order to increase SOA and minimally modify prime visibility, we maintained prime and post-mask duration at $44 \mathrm{~ms}$, and inserted a $44 \mathrm{~ms}$ blank screen before target. Would phonological repair effects appear more clearly for this longer SOA?

Method

Participants. Twenty-nine Spanish students drawn from the same population as in Experiments 1-2 participated in this experiment for course credit. They did not participate in the preceding experiments and reported no deficit in vision, audition, or language use.

Stimuli and design. Identical to that used in Experiment 1.

Procedure. Stimulus presentation differed from that used in Experiment 2 in that a $44 \mathrm{~ms}$ blank screen was inserted before target onset. In this way, prime-to-target SOA was $132 \mathrm{ms,}$ while prime and post-mask durations were maintained at $44 \mathrm{~ms}$.

Results

The results are summarized in Table 4 . The missing data amounted to $0.91 \%$ of the data. Eight test target words (four from each of the "astuto" and "especial" categories) induced more than $40 \%$ errors and were thus discarded from the analyses. Analyses of variance were performed as in Experiments 1-2 on the RT and error data, with the same factors Target type and Priming condition. For the RT data, neither Target type nor Priming condition were significant but their interaction was significant, $F 1(1,28)=5.75, p<.05, \eta_{\mathrm{p}}^{2}=$ $0.170, F 2(1,38)=6.42, p<.05, \eta_{\mathrm{p}}^{2}=0.145$. For “astuto" targets, RTs were longer after 
partial (sC-) than after full (asC-) repetition primes (822 vs. $767 \mathrm{~ms}), F 1(1,28)=12.56, p<$ $.005, \eta_{\mathrm{p}}^{2}=0.310, F 2(1,19)=10.82, p<.005, \eta_{\mathrm{p}}^{2}=0.363$. The opposite trend for "especial" targets (longer RTs after full repetition) did not reach significance, $F_{\mathrm{s}}<1$. No significant effect of the main factors or interaction was found in the error data but there were (nonsignificant) numerical trends for less errors with "astuto" than with "especial" targets (7.2 vs. $9.0 \%)$ and for more errors in the full than in the partial repetition condition (8.8 vs. $7.4 \%){ }^{6}$

— Table 4 about here -

Target length correlated positively with RT, regardless of priming condition or target type $(p s<.005)$, but not with alteration effect $(p s>.2)$. Target word frequency tended to correlate negatively with RT but, again, not with alteration effect. Covariance analyses on the items data, with target length or target frequency as a covariate, further supported the lack of interference of target length or frequency with the general pattern of results. After factoring out the covariate, the Target type $\mathrm{x}$ Priming condition interaction remained significant $(p \mathrm{~s}<$ .05), with significantly shorter RTs for full than partial repetition for "astuto" targets and the opposite, nonsignificant trend for "especial" targets. Finally, we looked at the subjects data according to individual response speed: the alteration effect did not correlate with subjectwise average $\mathrm{RT}$, for either asC- or esC- words.

These results suggest that, after a delay of more than $100 \mathrm{~ms}$, the $\mathrm{sC}$ - primes activate a phonological code which is congruent with esC- but not asC- targets. A plausible account for this contrasted pattern of results is that, after some $100 \mathrm{~ms}$ of covert processing of the subliminal prime (prime duration was maintained at $44 \mathrm{~ms}$ ), orthographic code activation has decayed substantially while phonological code activation has built up and become congruent with target, but only for those primes that can be phonologically repaired into their associated target. The phonological code whose influence is observed here must therefore incorporate 
the ${ }_{s} C \rightarrow e s C$ repair. We call the differential effect obtained with primes such as "stuto" versus "special" the "phonological repair effect." The issue of the time-course of phonological code activation in this particular case, in which a repair mechanism takes place, will be taken over in the General Discussion.

So far, the asC- words were restricted to words such as "astuto" and "oscuro." Words such as "historia" or "hospital" have been deliberately avoided even though ' $h$ ' is not pronounced in Spanish. Because there is no esC- words spelled with an initial ' $h$ ' in Spanish, deleting the phonetic word-initial vowel in $\mathrm{VsC}$ - words entails deleting two letters in the written form of ' $h$ '-initial asC- words, and only one in esC- words. Therefore, less priming for storia-HISTORIA than for special-ESPECIAL could conceivably be explained by less orthographic overlap rather than by the phonological repair that would repair storia into estoria. This is the reason why we avoided such ' $h$ ' items. But now that we have established the phonological nature of the repair effect, we may predict that all the asC- words behave in the same way, whether they are spelled with an initial ' $h$ ' or not. To test for this prediction, we included ' $h$ '-initial asC- target words in Experiment 4.

The main motivation of Experiment 4, however, is to replicate the phonological repair effect with a different set of word stimuli (including 'h' words). Indeed, a subset of about 10 infrequent asC- and esC- targets led to many lexical decision errors in Experiments 1-3. In Experiment 4, we replaced those error-prone words with more familiar words.

\section{Experiment 4}

Experiment 4 attempted to replicate the phonological repair effect found in Experiment 3, using substantially different sets of esC- and asC- target words, including ' $h$ '- 
initial asC- words such as "historia" and "histeria." A second issue is whether the alteration effects with these ' $h$ '-initial items differ from those with vowel-letter-initial asC- items.

\section{Method}

Participants. Thirty-four Spanish students drawn from the same population as in

Experiments 1-3 participated in this experiment for course credit. They did not participate in the preceding experiments and reported no deficit in vision, audition, or language use.

Stimuli and design. We used only six 'h'-initial and 20 vowel-letter-initial asC- words because (1) the number of ' $h$ '-initial asC- words in Spanish is limited (although most of these words are frequent in Spanish) ${ }^{7}$ and (2) the frequent occurrence in the experiment of ' $h$ 'initial targets might be noticed by participants over the course of the experiment. Importantly, the numbers of ' $h$ '-initial (six) and vowel-initial (20) asC- words used here roughly reflect the proportions observed in Spanish.

Eleven new asC- words, among which six ' $h$ '-initial words, were added to the materials. They replaced nine asC- words amongst the 24 used in Experiments 1-3: in particular, the words that induced many errors in Experiments 1-3, which presumably were rare words for many Spanish listeners, were replaced. This made a total of 26 test asC- target words of the "astuto" type. A new set of 26 target words of the "especial" type was constructed to match the "astuto" type of target words, with only two items retained from the set used in Experiments 1-3 (see Appendix C). The asC- and esC- words were matched for frequency of occurrence (26.4 vs. 26.6 o.p.m; 0.67 vs. $0.69 \log$ frequency, respectively), number of syllables (3.8 vs. 3.4), and number of letters (8.7 vs. 7.6); only the latter numerical difference reached significance, $t(50)=2.65, p<.05$. The lexical frequencies of these target 
words were, in average, about twice as high as those in Experiment 1-3 (due in part to the ' $h$ ' words, see Footnote 7).

As in the preceding experiments, the prime-target pairs were split into two lists so that priming condition (partial vs. full repetition priming) and target type (“especial" vs. "astuto" words) were counterbalanced across the two lists. Half of the participants received one list, and the other half the other list, so that each participant was presented with all of the 52 test targets but only once. Each participant also received the same 90 filler prime-target pairs as in Experiments 1-3 and was trained with the same set of nine practice prime-target pairs.

Procedure. Identical to that used in Experiment 3.

Results and discussion

The results are summarized in Table 5 . The missing data amounted to $0.80 \%$ of the data. Four test target (“ostensible," "ostracismo," "estado," and "esqueje”) produced more than $40 \%$ errors and were discarded from the analyses. Analyses of variance were performed first on the RT and error data for all the retained items (i.e., including ' $h$ '-initial items), with the same Target type and Priming condition factors as in Experiment 3.

- Table 5 about here -

For the RT data, Target type and Priming condition had not significant effect overall but the Target type $x$ Priming condition interaction was significant, $F 1(1,33)=9.41, p<.005$, $\eta_{\mathrm{p}}^{2}=0.222, F 2(1,46)=5.77, p<.05, \eta_{\mathrm{p}}^{2}=0.111$. As in Experiment 3, RTs for asC- targets were longer after partial than after full repetition primes ( 899 vs. $857 \mathrm{~ms}), F 1(1,33)=4.94$, $p<.05, \eta_{\mathrm{p}}^{2}=0130, F 2(1,23)=4.18, p=.052($ marginal $), \eta_{\mathrm{p}}^{2}=0.154$. The opposite trend (RTs shorter by $25 \mathrm{~ms}$ after partial than full repetition) held for esC- targets but was significant only in the subjects analysis, $F 1(1,33)=4.47, p<.05, \eta_{\mathrm{p}}^{2}=0.101, F 2(1,23)=$ 
$1.93, p=.18$. The results are thus similar to those obtained in Experiment 3. For the error data, Target type was not significant; Priming condition was significant, $p \mathrm{~s}<.05$, with more errors in the partial than full repetition condition ( $8.6 \%$ vs. $5.8 \%)$. The Priming $\mathrm{x}$ Target interaction was far from significance, $F \mathrm{~s}<1$. Thus, unlike in Experiment 3, there was no sign of a speed-accuracy trade-off in the data for either the esC- or asC-targets.

Target length correlated positively with RT, for almost all priming conditions and target types $(p s<.05),{ }^{8}$ but not with the alteration effect $(p s>.2)$. Target word frequency tended to correlate negatively with RT but, again, not with the alteration effect ( $p s>.2)$. Covariance analyses of the items data further showed that target length or frequency did not interfere with the overall pattern of results: after either target length or frequency had been factored out, the Target type $\mathrm{x}$ Priming condition interaction remained significant $(p s<.05)$. Finally, the alteration effect did not correlate with subject-wise average RT, either for asC- or esC-words $(r(32)=0.13$ and $-0.01, n . s$, respectively $)$.

Experiment 4 also asked whether the 'h' stimuli (e.g., "historia") behave differently from the vowel-letter-initial stimuli (e.g., "astuto"). As can be seen in Table 5, the pattern of results for the $\mathrm{V} \neq / \mathrm{e} /$ targets is similar for ' $\mathrm{h}$ '-initial and vowel-initial targets, although the 20 ms advantage for the full over the partial repetition priming condition did not reach significance (note that the number of observations was very limited). Targets such as "histeria" were responded faster overall than those such as "astuto" (827 vs. $878 \mathrm{~ms}), F 1(33)$ $=4.88, p<.05, \eta_{\mathrm{p}}^{2}=0.129$. As this difference is, for the most part, explained by the difference in target length and frequency between words with and without an initial ' $h$ ', 9 we may consider that ' $h$ '- and vowel-letter-initial asC- target words behaved in essentially the same way: they were responded faster in the full than in the partial repetition condition. In contrast, the esC- targets such as "especial" tended to be responded faster in the partial than in the full repetition condition. Introducing some ' $\mathrm{h}$ '-initial words in the set of asC- targets actually did 
not alter the pattern of results. We ran analyses on the data obtained after excluding the six 'h'-initial words. No significant effect of the main factors was found in the RT data, but a significant Target $x$ Priming type interaction obtained in the RT data, $F 1(1,33)=9.76, p<$ $.005, \eta_{\mathrm{p}}^{2}=0.228, F 2(1,40)=6.50, p<.05, \eta_{\mathrm{p}}^{2}=0.140$, reflecting a significantly positive alteration effect (42 ms) for the asC- target type, $F 1(1,33)=6.0, p<.05, \eta_{\mathrm{p}}^{2}=0.154, F 2(1$, $17)=5.88, p=.05, \eta_{\mathrm{p}}^{2}=0.257$, and a negative effect for the esC- target type, significant only in the subjects analysis (see above). As for the error data, just like in the analyses including ' $h$ ' items, only Priming condition was significant, $p s<.05$, with more errors in the partial than full repetition condition (9.4\% vs. $6.1 \%)$.

The results of Experiment 4 thus largely replicated those of Experiment 3: the addition within the asC- word set of ' $h$ '-initial words such as "histeria" did not alter the general pattern of results: alteration effects for asC- target words, no such effects for esC- target words. Alteration effects could have been larger with prime-target pairs such as steria-HISTERIA than stuto-ASTUTO because they have more orthographic mismatch between prime and target. Such was not the case (20 ms and $42 \mathrm{~ms}$ alteration effects, respectively), however, lending even more support to the conclusion that the alteration effect is not related to the amount of graphic mismatch and is mainly determined by the phonological mismatch between prime and target generated by the ${ }_{s} C \rightarrow e s C$ repair. The pattern of results for the ' $\mathrm{h}$ ' target words, although based on few items, is in line with the hypothesis that phonological code dominates over graphic code after about $100 \mathrm{~ms}$ prime exposure. For the targets of the "especial" category, there is simply no alteration effect: RTs are even faster in the partial than in the full repetition condition, as was found in Experiment 3. We will discuss this aspect of the data in the General Discussion.

\section{General Discussion}


The key finding of this study is the very different efficacy of sC- partial repetition primes, in Experiments 3-4, according to whether they are derived from an esC- or an asCword. The orthographic mismatch between prime and target is no larger for the asC- than for the esC- targets. Yet we found that "astuto" is significantly less primed by "stuto" than by itself, whereas the opposite trend holds for "especial." This difference is robust at a rather long prime-target SOA $(132 \mathrm{~ms})$; it emerges for a medium SOA $(88 \mathrm{~ms})$ and is not observed at all for the shortest SOA (44 ms), at which the target immediately follows the prime.

The different fate of the stuto-ASTUTO and special-ESPECIAL pairs must be related to the phonological code constructed from the prime after the ${ }_{s} C \rightarrow e s C$ phonological repair has applied: estuto (a nonword from "stuto)," vs. especial (a word from "special"). It cannot be related to orthographic mismatch because there is no less orthographic mismatch in the "astuto" than in the "especial" pairs in Experiment 3. Moreover, the similar results for ' $h$ ' and no-' $h$ ' asC- items in Experiment 4 suggest that the amount of orthographic mismatch does not affect alteration effects. Finally, because orthographic mismatch is proportionally larger for shorter targets, the absence of a correlation between target length and alteration effect, throughout the entire study, also supports this conclusion.

How else could the "astuto" and "especial" items differ? The two categories of targets do differ with respect to the number of word types in their respective categories. As noted earlier, esC- words largely dominate asC- words in terms of number of word types (five times as many esC- as asC- word types). Yet, how would this difference modulate priming effects? We can only surmise that more word types entails more competitors and, therefore, that the esC- targets could, in general, be responded less rapidly than the asC- targets. ${ }^{10}$ The results, however, show that responses to asC- targets, not to esC- targets, are slower in the partial than in the full repetition priming condition. This pattern of results cannot be explained by the 
lesser competition for asC- than for esC-words. The phonological repair account thus seems the only viable explanation for the difference between the stuto-ASTUTO and special-ESPECIAL pairs, licensing the label of "phonological repair effect."

That the same phonological repair, ${ }_{s} C \rightarrow e s C$, is induced by the letter string "sC" and by its letter by letter phonemic counterpart provides a positive answer to one issue raised in the Introduction: letter strings are processed as if they were directly and sequentially translated into their phonemic counterparts, at least for a language such as Spanish, which has a regular and transparent orthography. Phoneme or letter order and position are crucial here because the repair mechanisms at stake bear on a case of phonotactic transgression: it is indeed the ordered sequence of a word-initial 's' followed by a consonant, that is first mapped to $/ \mathrm{sC} /$, then repaired into $/ \mathrm{esC} /$. The critical importance of letter order and position in this study is thus in line with those models of visual word recognition that assume a sequential letter-to-sound conversion in phonological activation (Carreiras, Ferrand, Grainger, \& Perea, 2005; Coltheart, Rastle, Perry, Langdon, \& Ziegler, 2001; Taft, 1979, 1991). It is important to note, however, that, in our study, the phonological repair effect was only found for prime-target pairs with a long SOA, not for immediate succession of prime and target, and was just emerging at an intermediate SOA. As we have suggested, this might be due to the slower time course of activation of phonological than orthographic code. In the materials we used, an additional reason why phonological activation lags behind orthographic activation could be the increased amount of time required for a phonological code to build up when phonological repair is involved. We will return to this issue in discussing the slight advantage for the "special" over the "especial" primes.

In the situation under scrutiny in the present study, the presumably non-conscious phonological code construction incorporates the ${ }_{s} C \rightarrow e s C$ phonological repair specific to Spanish. The automatic nature of the construction of a phonological code suggests that 
language-specific phonological repairs likely become an integral part of phonological activation from print, as reading abilities develop. Phonological repairs become, for fluent readers, built-in rather than epiphenomenal to the letter-to-sound conversion process.

Finally, the automatic nature of the pre-activation mechanisms in visual masked priming together with their presumably prelexical locus, suggest that phonological repairs of speech inputs are themselves automatic and prelexical. That is, assuming that the basic repair mechanisms are the same for speech and for print and apply to the same phonological code, our results also bear on the issue of the nature and locus of the phonological repair mechanisms in speech perception: the perceptual shifts, assimilations, or phonotactic repairs reported in the speech perception literature would also be automatic and prelexical (also see Dupoux et al., 2001).

An interesting and somewhat puzzling aspect of the data of Experiments 3 and 4 is the greater efficacy of "special" than "especial" in priming especial. The relevant difference in response latencies reached statistical significance in the subjects analysis of Experiment 4. Across experiments 3 and 4, the mean $23 \mathrm{~ms}$ difference is not far from significance, $t 1(62)=$ $1.68, p=.098, t 2(43)=1.56, p=.127$. It is reliable enough, we believe, to deserve a tentative interpretation. The puzzling outcome of lesser priming with full than partial repetition primes might be explained in terms of the time course of activation metaphor, applied to the phonological code of the prime, assumed to pre-activate target. An alternative metaphor is that of prime-target redundancy: as the phonological code of the prime builds up in time (or reaches "coherence": see, among other similar views, Van Orden \& Kloos, 2005), primetarget redundancy increases (in particular, at the phonological level). Common to both metaphors, however, is the notion that there is a rise-then-decline in time of any phonological priming effect induced by a subliminal prime. In Experiments 3-4, at the moment when the 
"especial" target is presented, $132 \mathrm{~ms}$ after prime onset, the phonological activation of "especial" must have reached a maximum and begun to decline somewhat earlier after the "especial" than after the "special" prime. Why should it be so? In the case of "special," phonological activation of /espe $\theta \mathrm{jal} /$ engages not only letter-to-sound conversion but also phonological repair. Accordingly, while the same code is eventually built from the "special" or "especial" primes, there is some additional time cost with the former prime, entailing delay in both rise and decline of activation. Note that additional time cost is often observed in speech processing, whenever the speech input deviates from the native phonology in some way, and is subsequently perceptually repaired. For example, French listeners are slower to detect $/ \mathrm{k} /$ in tlabdo (repaired into klabdo) than in klabdo (Hallé et al., 1998); they also are slower to make a positive lexical decision on tlavier (repaired into clavier 'keyboard') than on the unaltered form clavier (Segui, Frauenfelder, \& Hallé, 2001); similarly, Dupoux et al. (2001) found a (nonsignificant) trend for Japanese listeners to be slower at making a positive lexical decision on sokdo (repaired into sokudo 'speed') than on sokudo; likewise, in French words such as chenille (/Sənij/ or /Snij/ 'caterpillar') word-medial schwa deletion generally slows down recognition (Racine \& Grosjean, 2005), and the additional processing-time correlates with the perceived unnaturalness of schwa deletion. Conceivably, then, adopting the activation metaphor for ease of reasoning, the time-course of the rise-and-decline of phonological activation of /espe $\theta \mathrm{jal} /$ from "special" could be delayed compared to that from "especial." This is consistent with the advantage for "especial" over "special" primes, at some point of their covert processing, which later turns to an opposite advantage for the "special" primes. Figure 1 illustrates that reversal when SOA has increased from 88 to 132 ms. For the "astuto" targets, there is no reversal, consistent with the assumption that "stuto" primes only lead to the "wrong" phonological code /estuto/. At 44 ms SOA (prime and target in immediate succession), full and partial repetition priming are equivalent for both the 
"astuto" and "especial" targets (Figure 1). We have argued that this pattern suggests a dominance of the orthographic code at short SOAs (at least for the rather long target words we used). If a phonological code has begun to build up, it has not been repaired yet because the altered primes "special" and "stuto" still induce equivalent priming.

\section{— Figure 1 about here -}

Let us return to the main finding of the present study, namely that suppressing a vowel letter in subliminal print or a vowel phoneme in speech both result in the perceptual prosthesis of a phonological vowel. It strongly suggests that phonological activations from print and from speech engage very similar, or perhaps identical processes and representations.

The latter assumption is in line with recent studies of phonological mediation in visual masked priming that have questioned the nature of the phonological code activated from print. First, this code may not be abstracted from details in the sense that its elemental units are phonemes. It seems to be detailed down to the level of phonetic features, as suggested by the recent work of Lukatela, Eaton, Lee, and Turvey (2001) showing that phonological priming in a visual masked priming is determined by phonetic feature overlap rather than by phonemic overlap. For example, "vea" primes "sea" less strongly than "zea," although both "vea" and "zea" differ from "sea" by just one phoneme (or letter), the phonetic feature overlap with "sea" is larger for "zea" than for "vea." Second, closer to articulatory-phonetic realization, evidence has been found that non distinctive vowel duration (as in bat vs. bad) is implicitly coded in the phonological representation generated by print (Abramson \& Goldinger, 1997; Lukatela, Eaton, Sabadini, \& Turvey, 2004). Such findings, if confirmed by further empirical investigation, show that the phonological code generated by print is "phonetically informed." Lukatela et al. (2004) propose that both speech and print rely on a common phonological representation based on gestural dynamics, in line with Alvin Liberman's (1996) 
"unconventional motor theory" and, more specifically, with his central -and provocativeclaim that speech and print share the same gestural code.

The data reported in the present study can also be regarded as supporting the assumption of a common phonological code for printed and spoken stimuli. Indeed, the effect we found in a visual masked priming situation is perfectly congruent with known effects in speech perception: the perception of an epenthetic/prothetic vowel in speech stimuli in which that vowel is physically absent. Recent advances in speech perception, as well as in loanword phonology, converge to suggest that perceived phonetic similarity is a central factor in determining how nonnative speech input is repaired or adapted to the native sound system (Hallé, Best, \& Levitt, 1999; Silverman, 1992; Vendelin \& Peperkamp, 2004; Yip, 1993). This would mean that native speakers of Spanish tend to hear [stid] as [estid] because [estid] is, for them, a better phonetic match than other conceivable repairs such as [setid], [sid], or [tid]. On Lukatela et al.'s (2004) view, a better phonetic match is a better match in terms of gestural dynamics. The intriguing speculation with regards to repair from print is that a deviant letter string such as "stuto" is automatically mapped with the succession of "gestural scores" that corresponds to [estuto]. The gestural dynamics account suggests that, during reading acquisition, Spanish would-be readers learn to map sequences such as "st" directly to the gestural dynamics for [st], rather than first to the phonemic sequence $/ \mathrm{s} /+/ \mathrm{t} /$, as an account in terms of a linear letter-to-sound mapping would hold. When "st" occurs word-initially, the gestural dynamics is automatically repaired to that for [est]. In other words, we suggest that learning to read is learning to associate letter combinations to the same gestural dynamics representations that underlie speech perception and production. Less controversially, our findings, and those of Lukatela and colleagues, support the widely shared opinion that reading is phonemically mediated, and that both phonology and orthography contribute to visual word 
recognition (see, among others, Grainger \& Ferrand, 1996). The qualification we would like to add is that the relevant phonology is "gesturally" motivated.

However speculative is the account we propose, following the views of Lukatela and colleagues, the finding of the same repair mechanisms in print as those reported in speech at a low level of phonetic perception suggests that reading and listening rely on the same phonological code, prone to the same language-specific adjustments to phonetic variation. This finding thus adds some substance to the early claims made by Liberman and Mattingly that a single "language module" can take as input acoustic signals indeed, but also schematic linguistic descriptions such as those conventionally provided by print (Liberman, 1996; Liberman \& Mattingly, 1985; Mattingly, 1991). 


\section{References}

Abramson, M., \& Goldinger, S. (1997). What the reader's eye tells the mind's ear: Silent reading activates inner speech. Perception and Psychophysics, 59, 1059-1068.

Alameda, J. R. \& Cuetos, F. (1995). Diccionario de Frecuencias de las Unidades Linguïsticas del Castellano. Oviedo: Servicio de Publicaciones de la Universidad de Oviedo.

Balota, D.A., Cortese, M.J., Hutchison, K.A., Neely, J.H., Nelson, D., Simpson, G.B., \& Treiman, R. (2002). The English Lexicon Project: A web-based repository of descriptive and behavioral measures for 40,481 English words and nonwords.

http://elexicon.wustl.edu/, Washington University.

Berent, I., \& Perfetti, C. (1995). A rose is a reez: The two-cycles model of phonology assembly in reading English. Psychological Review, 102, 146-184.

Best, C. (1995). A direct realist perspective on cross-language speech perception. In W. Strange \& J. J. Jenkins (Eds.), Speech perception and linguistic experience: Issues in cross-language research, (pp. 171-204). Timonium, MD: York Press.

Bonnet, E., \& Lloret, M-R. (1998). Fonologia catalana. Barcelona: Editorial Ariel.

Câmara Jr., J.M. (1969). Problemas de lingüistica descritiva. Pertopolis: Vozes.

Carreiras, M., Ferrand, L., Grainger, J., \& Perea, M. (2005). Sequential effects of phonological priming in visual word recognition. Psychological Science, 16, 585-589.

Chéreau, C., Hallé, P., \& Segui, J. (in revision). Two-way interactions between orthography and phonology in both speech and print. Memory and Cognition.

Coltheart, M., Rastle, K., Perry, C., Langdon, R., \& Ziegler, J. (2001). DRC: A dual route cascaded model of visual word recognition and reading aloud. Psychological Review, $108,204-256$. 
Dupoux, E., Kakehi, Y, Hirose, C., Pallier, C., \& Mehler, J. (1999). Epenthetic vowels in Japanese: a perceptual illusion? Journal of Experimental Psychology: Human Perception and Performance, 25, 1568-1578.

Dupoux, E., Pallier, C., Kakehi, Y., \& Mehler, J. (2001). New evidence for prelexical phonological processing in word recognition. Language and Cognitive Processes, 16, 491-505.

Ferrand, L. \& Grainger, J. (1993). The time-course of phonological and orthographic code activation in the early phases of visual word recognition. Bulletin of the Psychonomic Society, 31, 119-122.

Ferrand, L., \& Grainger, J. (1994). Effects of orthography are independent of phonology in masked form priming. Quarterly Journal of Experimental Psychology, 47, 365-382.

Forster, J.C., \& Forster, K.I. (2003). DMDX: a Windows display program with millisecond accuracy. Behavior Research Methods, Instruments, \& Computers, 35, 116-124.

Frost, R. (1994). Prelexical and postlexical strategies in reading: Evidence from a deep and a shallow orthography. Journal of Experimental Psychology: Learning, Memory, and Cognition, 20, 116-129.

Frost, R. (1998). Toward a strong phonological theory of visual word recognition: True issues and false trails. Psychological Bulletin, 123, 71-99.

Grainger, J., \& Ferrand, L. (1994). Phonology and orthography in visual word recognition: Effects of masked homophone primes. Journal of Memory and Language, 33, 218-233.

Grainger, J., \& Ferrand, L. (1996). Masked orthographic and phonological priming in visual word recognition and naming: Cross-task comparisons. Journal of Memory and Language, 35, 623-647

Guo, T-M., Peng, D-L., \& Liu, Y. (2005). The role of phonological activation in the visual semantic retrieval of Chinese characters. Cognition, 98, B21-B34. 
Hallé, P., \& Best, C. (2007). Dental-to-velar perceptual assimilation: A cross-linguistic study of the perception of dental stop+/1/ clusters. Journal of the Acoustical Society of America, $121,2899-2914$.

Hallé, P., Best, C., \& Levitt, A. (1999). Phonetic vs. phonological influences on French listeners' perception of American English approximants. Journal of Phonetics, 27, 281306.

Hallé, P., \& Segui, J. (2003, September). Special is especial: Perception and production biases in Spanish with /sp, st, sk/-initial pseudowords. Communication presented at the ESCOP meeting, Granada, Spain.

Hallé, P., Segui, J., Frauenfelder, U., \& Meunier, C. (1998). Processing of illegal consonant clusters: A case of perceptual assimilation? Journal of Experimental Psychology: Human Perception and Performance, 24, 592-608.

Harris, J. (1983). Syllable structure and stress in Spanish: A nonlinear analysis. Linguistic Inquiry Monographs, 8, Cambridge: MIT Press.

Kim, J., \& Davis, C. (2002). Using Korean to investigate phonological priming effects without the influence of orthography. Language and Cognitive Processes, 17, 569-591.

Lesch, M.F., \& Pollatsek, A. (1993). Automatic access of semantic information by phonological codes in visual word recognition. Journal of Experimental Psychology: Learning, Memory, and Cognition, 19, 285-294.

Lesch, M.F., \& Pollatsek, A. (1998). Evidence for the use of assembled phonology in accessing the meaning of printed words. Journal of Experimental Psychology: Learning, Memory, and Cognition, 24, 573-592.

Liberman, A. M. (1996). Speech: A special code. Cambridge, MA: MIT Press.

Liberman, A. M., \& Mattingly, I. G. (1985). The Motor Theory of Speech Perception revised. Cognition, 21, 1-36. 
Lukatela, G., Eaton, T., Lee, C-H., Carello, C., \& Turvey, M. (2002). Equal homophonic priming with words and pseudohomophones. Journal of Experimental Psychology: Human Perception and Performance, 28, 3-21.

Lukatela, G., Eaton, T., Lee, C-H., \& Turvey, M. (2001). Does visual word identification involve a sub-phonemic level? Cognition, 78, B41-52.

Lukatela, G., Eaton, T., Sabadini, L., \& Turvey, M. (2004). Vowel duration affects word identification: Evidence that the mediating phonology is phonetically informed. Journal of Experimental Psychology: Human Perception and Performance, 30, 151-162.

Lukatela, G., Frost, S. J., \& Turvey, M. T. (1999). Identity priming in English is compromised by phonological ambiguity. Journal of Experimental Psychology: Human Perception and Performance, 25, 775-790.

Lukatela, G., \& Turvey, M. (1994). Visual lexical access is initially phonological: 2. Evidence from associative priming by homophones, and pseudohomophones. Journal of Experimental Psychology: General, 123, 331-353.

Mattingly, I. G. (1991). Reading and the biological function of linguistic representations. In I.G. Mattingly \& M. Studdert-Kennedy (Eds.), Modularity and the motor theory of speech perception (pp. 339-346). Hillsdale, NJ: Lawrence Erlbaum.

Massaro, D., \& Cohen, M. (1983). Phonological context in speech perception. Perception and Psychophysics. 34, 338-348.

McClelland, J.L., \& Elman, J.L. (1986). The TRACE model of speech perception. Cognitive Psychology, 18, 1-86.

New, B., Ferrand, L., Pallier, C., \& Brysbaert, M. (2006). Re-examining the word length effect in visual word recognition: New evidence from the English Lexicon Project. Psychonomic Bulletin and Review, 13, 45-52. 
Norris, D., McQueen, J.M., \& Cutler, A. (2000). Merging information in speech recognition: Feedback is never necessary. Behavioral and Brain Sciences, 23, 299-370.

O’Regan, J.K., \& Jacobs, A.M. (1992). Optimal viewing position effect in word recognition: A challenge to current theory. Journal of Experimental Psychology : Human Perception and Performance, 18, 185-197

Paradis, C., \& LaCharité, D. (1997). Preservation and minimality in loanwoard adaptation. Journal of Linguistics, 33, 379-430.

Perfetti, C., \& Bell, L. (1991). Phonemic activation during the first $40 \mathrm{~ms}$ of word identification: Evidence from backward masking and masked priming. Journal of Memory and Language, 30, 473-485.

Perfetti, C., \& Bell, L., \& Delaney, S. (1988). Automatic phonetic activation in silent word reading: Evidence from backward masking. Journal of Memory and Language, 27, 5970.

Perfetti, C., \& Tan, L-H. (1998). The time course of graphic, phonological, and semantic activation in Chinese character activation. Journal of Experimental Psychology: Learning, Memory, and Cognition, 24, 101-118.

Racine, I., \& Grosjean, F. (2005). Le coût de l'effacement du schwa lors de la reconnaissance des mots en français [Processing cost of schwa deletion in French word recognition]. Revue Canadienne de Psychologie Expérimentale, 59, 240-254.

Rayner, K., Sereno, S., Lesch, M., \& Pollatsek, A. (1995). Phonological codes are automatically activated during reading: Evidence from an eye movement paradigm. Psychological Science, 6, 26-32.

Segui, J., Frauenfelder, U., \& Hallé, P. (2001). Phonotactic constraints shape speech perception: Implications for sublexical and lexical processing. In E. Dupoux (Ed.), 
Language, brain, and cognitive development: essays in honor of Jacques Mehler (pp. 195-208). Cambridge, MA: MIT Press.

Silverman, D. (1992). Multiple scansions in loanword phonology: Evidence from Cantonese. Phonology, 9, 289-328.

Smithson, H., \& Mollon, J. (2006). Do masks terminate the icon? Quarterly Journal of Experimental Psychology, 59, 150-160.

Taft, M. (1979). Lexical access via an orthographic code: The BOSS. Journal of Verbal Learning and Verbal Behavior, 18, 21-39.'

Taft, M. (1991). Reading and the mental lexicon. Hove, England: Erlbaum.

Tan, L-H., Hoosain, R., \& Peng, D-L. (1995). Role of early presemantic phonological code in Chinese character identification. Journal of Experimental Psychology: Learning, Memory, and Cognition, 21, 43-54.

Tan, L-H., \& Perfetti, C. (1999). Phonological and associative inhibition in the early stages of English word identification: Evidence from backward masking. Journal of Experimental Psychology: Human Perception and Performance, 25, 59-69.

Theodore, R.M., \& Schmidt, A.M. (2003). Perceptual prothesis in native Spanish speakers. Journal of the Acoustical Society of America, 113 [abstract], 2256.

Townsend, J. T., \& Ashby, F. G. (1983). Stochastic modelling of elementary psychological processes. London: Cambridge University Press.

Van Orden, G., Holden, J., Podgornik, M., \& Aitchinson, C. (1999). What swimming says about reading: Coordination, context, and homophone errors. Ecological Psychology, 11, 45-79.

Van Orden, G., \& Kloos, H. (2005). The question of phonology and reading. In M. Snowling \& C. Hulme (Eds.), The science of reading: A handbook (pp. 61-78). Blackwell Publishing. 
Vendelin, I., \& Perperkamp, S. (2004). Evidence for phonetic adaptation of loanwords: An experimental study. Proceedings of the 4th Journées d'Etudes Linguistiques de l’Université de Nantes (pp. 127-132).

Yip, M. (1993). Cantonese loanword phonology and Optimality Theory. Journal of East Asian Linguistics, 2, 261-291.

Ziegler, J. C., \& Jacobs, A. M. (1995). Phonological information provides early sources of constraint in the processing of letter strings. Journal of Memory and Language, 34, 567593.

Ziegler, J. C., Van Orden, G. C., \& Jacobs, G. C. (1997). Phonology can help or hurt the perception of print. Journal of Experimental Psychology: Human Perception and Performance, 23, 845-860.

Zink, G. (1986). Phonétique historique du français. Paris: Presses Universitaires de France. 
Appendix A. Experiments 1-3 (lexical decision): asC- and esC- test targets with their number of syllables, of letters, occurrences per million, and log frequency. The associated primes were full repetition primes for one list and partial repetition primes for the other.

$$
\begin{array}{ll} 
& \text { "astuto" type } \\
\text { nsyl ncar opm logfreq }
\end{array}
$$

List 1

$\begin{array}{lllll}\text { aspecto } & 3 & 7 & 127.0 & 2.1 \\ \text { ustedes } & 3 & 7 & 68.0 & 1.8 \\ \text { astuto } & 3 & 6 & 5.5 & 0.8 \\ \text { astilla } & 3 & 7 & 2.0 & 0.5 \\ \text { astado } & 3 & 6 & 0.5 & 0.2 \\ \text { astracán } & 3 & 8 & 0.5 & 0.2 \\ \text { asqueroso } & 4 & 9 & 4.0 & 0.7 \\ \text { ostentoso } & 4 & 9 & 2.5 & 0.5 \\ \text { astillero } & 4 & 9 & 1.5 & 0.4 \\ \text { aspiradora } & 5 & 10 & 0.5 & 0.2 \\ \text { astigmatismo } & 5 & 12 & 0.0 & 0.0 \\ \text { osteoporosis } & 6 & 12 & 0.5 & 0.2 \\ \text { means } & \underline{3.8} & \underline{8.5} & \underline{17.7} & \underline{0.63}\end{array}$

$\underline{\text { List } 2}$

$\begin{array}{lllll}\text { oscuro } & 3 & 6 & 77.0 & 1.9 \\ \text { áspero } & 3 & 6 & 11.0 & 1.1 \\ \text { astenia } & 3 & 7 & 0.5 & 0.2 \\ \text { isquemia } & 3 & 8 & 0.0 & 0.0 \\ \text { asturiano } & 4 & 9 & 5.0 & 0.8 \\ \text { aspirante } & 4 & 9 & 3.0 & 0.6 \\ \text { astrónomo } & 4 & 9 & 2.0 & 0.5 \\ \text { aspaviento } & 4 & 10 & 2.0 & 0.5 \\ \text { aspirina } & 4 & 8 & 1.0 & 0.3 \\ \text { astringente } & 4 & 11 & 0.5 & 0.2 \\ \text { asterisco } & 4 & 9 & 0.0 & 0.0 \\ \text { asteroide } & 5 & 9 & 0.5 & 0.2 \\ \text { means } & \underline{3.8} & \underline{8.4} & \underline{8.5} & \underline{0.51}\end{array}$

grand means

$S D s$ “especial” type

nsyl ncar opm logfreq

$\begin{array}{lllll}\text { espejo } & 3 & 6 & 103.5 & 2.0 \\ \text { estación } & 3 & 8 & 74.0 & 1.9 \\ \text { estaca } & 3 & 6 & 4.0 & 0.7 \\ \text { estrado } & 3 & 7 & 1.5 & 0.4 \\ \text { estaño } & 3 & 6 & 0.5 & 0.2 \\ \text { estrofa } & 3 & 7 & 2.0 & 0.5 \\ \text { esquiador } & 4 & 9 & 0.5 & 0.2 \\ \text { estilista } & 4 & 9 & 0.5 & 0.2 \\ \text { estilete } & 4 & 8 & 2.0 & 0.5 \\ \text { espiritismo } & 5 & 11 & 0.5 & 0.2 \\ \text { estercolero } & 5 & 11 & 0.5 & 0.2 \\ \text { estancamiento } & 13 & 1.5 & 0.4 \\ & \underline{3.8} & \underline{8.4} & \underline{15.9} & \underline{0.60}\end{array}$

$\begin{array}{lllll}\text { escrito } & 3 & 7 & 97.5 & 2.0 \\ \text { espina } & 3 & 6 & 7.5 & 0.9 \\ \text { estola } & 3 & 6 & 0.5 & 0.2 \\ \text { esquirol } & 3 & 8 & 0.5 & 0.2 \\ \text { estúpido } & 4 & 8 & 13.0 & 1.1 \\ \text { espinaca } & 4 & 8 & 0.5 & 0.2 \\ \text { estropajo } & 4 & 9 & 1.0 & 0.3 \\ \text { espátula } & 4 & 8 & 0.5 & 0.2 \\ \text { espumoso } & 4 & 8 & 1.5 & 0.4 \\ \text { estadista } & 4 & 9 & 1.5 & 0.4 \\ \text { estropicio } & 4 & 10 & 1.5 & 0.4 \\ \text { estafeta } & 4 & 8 & 1.0 & 0.3 \\ & \underline{3.7} & \underline{7.9} & \underline{10.5} & \underline{0.55} \\ & \underline{3.7} & \underline{8.2} & \underline{13.2} & \underline{0.57} \\ & \underline{0.69} & 1.79 & \underline{30.8} & 0.59\end{array}$


Annexe B. Experiment 2 (prime visibility test): targets of filler trials with their associated "different" primes in each of the two counterbalanced lists ( $S D$ between parentheses).

List 1

\begin{tabular}{|c|c|c|c|c|c|c|c|}
\hline Prime & ncar & Target & ncar & Prime & ncar & Target & ncar \\
\hline saturno & 7 & pequeña & 7 & tozudo & 6 & animal & 6 \\
\hline ordeno & 6 & fianza & 6 & termitas & 8 & programa & 8 \\
\hline puñeta & 6 & tirano & 6 & soltar & 6 & batida & 6 \\
\hline canturrea & 9 & perdición & 9 & moquetero & 9 & sabandija & 9 \\
\hline tisana & 6 & ballenero & 9 & impotente & 9 & patronato & 9 \\
\hline damero & 6 & fiable & 6 & castaña & 7 & geólogo & 7 \\
\hline doraditos & 9 & bandoneón & 9 & tortugas & 8 & gimnasio & 8 \\
\hline fantástica & 10 & berberecho & 10 & contrapisas & 11 & saneamiento & 11 \\
\hline conato & 6 & perola & 6 & sumisa & 6 & boceto & 6 \\
\hline secantes & 8 & biógrafo & 8 & vomitar & 7 & geranio & 7 \\
\hline turientas & 9 & calificativo & 12 & botafumeiro & 11 & lubricantes & 11 \\
\hline destinataria & 12 & californiano & 12 & urbanización & 12 & telespectador & 13 \\
\hline trucho & 6 & gracia & 6 & tumbona & 7 & materia & 7 \\
\hline cantar & 6 & recreo & 6 & cancha & 6 & obrero & 6 \\
\hline rumiantes & 9 & catecismo & 9 & deuterio & 8 & basílica & 8 \\
\hline pantuflas & 9 & combinado & 9 & antelina & 8 & plutonio & 8 \\
\hline tostadora & 9 & corolario & 9 & sensación & 9 & pastelero & 9 \\
\hline abombonado & 10 & compositor & 10 & esclavas & 8 & polígono & 8 \\
\hline estirada & 8 & panfleto & 8 & postrada & 8 & serrucho & 8 \\
\hline tartamudo & 9 & fiambrera & 9 & amplísima & 9 & petrolero & 9 \\
\hline cántico & 7 & fijador & 7 & bonete & 6 & pelusa & 6 \\
\hline histriónico & 11 & silenciador & 11 & oscilantes & 10 & geométrico & 10 \\
\hline pasmarote & 9 & ferretero & 9 & catalina & 8 & sectario & 8 \\
\hline mescalina & 9 & papagallo & 9 & escelsas & 8 & ruiseñor & 8 \\
\hline means & $\underline{8.2}$ & & $\underline{8.4}$ & & $\underline{8.1}$ & & 2 \\
\hline
\end{tabular}

List 2

car

grand means
Prime $(\neq$ target $)$
Target
$8.15(1.70)$
$8.29(1.81)$ 
Appendix C. Experiment 4: asC- and esC- targets. The associated primes were full repetition primes for one list and partial repetition primes for the other.

$$
\begin{aligned}
& \text { "astuto" type } \\
& \text { nsyl ncar opm logfreq }
\end{aligned}
$$

List 1

$\begin{array}{lllll}\text { historia } & 3 & 8 & 402.0 & 2.6 \\ \text { hospital } & 3 & 8 & 28.0 & 1.5 \\ \text { astuto } & 3 & 6 & 5.5 & 0.8 \\ \text { histeria } & 3 & 8 & 4.0 & 0.7 \\ \text { ustedes } & 3 & 7 & 0.0 & 0.0 \\ \text { asqueroso } & 4 & 9 & 4.0 & 0.7 \\ \text { astrónomo } & 4 & 9 & 2.0 & 0.5 \\ \text { ostracismo } & 4 & 10 & 1.5 & 0.4 \\ \text { aspirante } & 4 & 9 & 3.0 & 0.6 \\ \text { asterisco } & 4 & 9 & 0.0 & 0.0 \\ \text { hostelería } & 5 & 10 & 1.5 & 0.4 \\ \text { astronauta } & 5 & 10 & 4.5 & 0.7 \\ \text { aspiradora } & 5 & 10 & 0.5 & 0.2 \\ \text { means } & \underline{3.8} & \underline{8.7} & \underline{35.1} & \underline{0.70}\end{array}$

\begin{tabular}{|c|c|c|c|c|}
\hline aspecto & 3 & 7 & 126.5 & 2.1 \\
\hline oscuro & 3 & 6 & 77.0 & 1.9 \\
\hline hispano & 3 & 7 & 9.0 & 1.0 \\
\hline astilla & 3 & 7 & 2.0 & 0.5 \\
\hline aspersor & 3 & 8 & 0.0 & 0.0 \\
\hline asturiano & 4 & 9 & 5.0 & 0.8 \\
\hline ostensible & 4 & 10 & 4.5 & 0.7 \\
\hline ostentoso & 4 & 9 & 2.5 & 0.5 \\
\hline hospedaje & 4 & 9 & 1.5 & 0.4 \\
\hline aspirina & 4 & 8 & 1.0 & 0.3 \\
\hline asteroide & 5 & 9 & 0.0 & 0.0 \\
\hline astigmatismo & 5 & 12 & 0.0 & 0.0 \\
\hline oscurantista & 5 & 12 & 0.0 & 0.0 \\
\hline means & $\underline{3.8}$ & $\underline{8.7}$ & $\underline{17.6}$ & $\underline{0.63}$ \\
\hline grand means & $\underline{3.8}$ & $\underline{8.7}$ & 26.4 & $\underline{0.67}$ \\
\hline$S D s$ & 0.78 & 1.54 & 81.6 & 0.68 \\
\hline
\end{tabular}

List 2

$$
\begin{gathered}
\text { "especial" type } \\
\text { nsyl ncar opm logfreq }
\end{gathered}
$$

$\begin{array}{lllll}\text { estado } & 3 & 6 & 375.5 & 2.6 \\ \text { estancia } & 3 & 8 & 27.0 & 1.4 \\ \text { escudo } & 3 & 6 & 9.0 & 1.0 \\ \text { establo } & 3 & 7 & 8.0 & 1.0 \\ \text { esponja } & 3 & 7 & 6.0 & 0.8 \\ \text { escultor } & 3 & 8 & 4.5 & 0.7 \\ \text { escaño } & 3 & 6 & 4.0 & 0.7 \\ \text { espora } & 3 & 6 & 0.0 & 0.0 \\ \text { esqueje } & 3 & 7 & 0.0 & 0.0 \\ \text { escarmiento } & 4 & 11 & 3.0 & 0.6 \\ \text { estornudo } & 4 & 9 & 1.5 & 0.4 \\ \text { estampilla } & 4 & 10 & 0.0 & 0.0 \\ \text { estofado } & 4 & 8 & 0.0 & 0.0 \\ & \underline{3.3} & \underline{7.6} & \underline{33.7} & \underline{0.71}\end{array}$

$\begin{array}{lllll}\text { estudio } & 3 & 7 & 143.5 & 2.2 \\ \text { escape } & 3 & 6 & 13.0 & 1.1 \\ \text { estanque } & 3 & 8 & 5.0 & 0.8 \\ \text { escoba } & 3 & 6 & 4.5 & 0.7 \\ \text { estanco } & 3 & 7 & 2.0 & 0.5 \\ \text { estrofa } & 3 & 7 & 2.0 & 0.5 \\ \text { espasmo } & 3 & 7 & 0.0 & 0.0 \\ \text { escuela } & 4 & 7 & 81.0 & 1.9 \\ \text { escombrera } & 4 & 10 & 1.5 & 0.4 \\ \text { esterilla } & 4 & 9 & 1.0 & 0.3 \\ \text { espinaca } & 4 & 8 & 0.5 & 0.2 \\ \text { escalope } & 4 & 8 & 0.0 & 0.0 \\ \text { espinilla } & 4 & 9 & 0.0 & 0.0 \\ & \underline{3.5} & \underline{7.6} & \underline{19.5} & \underline{0.66} \\ & \underline{3.4} & \underline{7.6} & \underline{26.6} & \underline{0.69} \\ & \underline{0.50} & 1.39 & \underline{77.7} & 0.70\end{array}$




\section{Author Note}

This research was supported by a "Picasso" French-Spanish "Actions Intégrées" funding, grant number HF-2002-0006. We thank David Morales for his help in running the experiments. We also thanks Guy Van Orden and two anonymous reviewers for their very positive advices to improve an earlier draft of this manuscript. 


\section{Footnotes}

1 "Phonological repair" usually refers to loanword adaptation in loanword phonology. In that context, words borrowed from a source language are introduced in the borrowing language by speakers who are presumably aware of the necessary adjustments for the loanword to comply with the target language phonology (Paradis \& LaCharité, 1997). Here, we use the phrase "phonological repair" in a somehow different way, referring to the repairs that are made at a perceptual level by naïve listeners who may not be aware of a phonological violation. The difference, however, is quite rhetorical if one adheres with the view that adaptations reflect layman perceptual assimilations (see Vendelin \& Peperkamp, 2004).

${ }^{2}$ Catalan and Portuguese have the same ban on word-initial $s C$ and also add a prothetic vowel to sC- loanwords. Catalan adds schwa (Bonnet \& Lloret, 1998) and Brazilian Portuguese adds /i/ (or sometimes /u/) as a prothetic vowel (Câmara Jr., 1969). The epenthetic vowel inserted in loanwords thus varies across languages. On a phonological account, it is motivated by markedness considerations: the borrowing language tends to choose its less marked vowel as the epenthetic vowels (e.g., /u/ in Japanese, the vowel most prone to deletion in phonological alternations). On a phonetic account, epenthetic vowels are the shortest and the most centralized vowel in a given language's phonetic space. Diachronically, a prothetic vowel before /s/+C appears in Latin as an articulatory device facilitating the pronunciation of /s/+C immediately after a consonant. Zink (1986), for instance, proposes that this prothetic vowel's function is to provide an articulatory "appui" [base] for /s/, and that it is "... articulée au plus près de $\mathrm{s} . . . "$ [articulatorily closest to $/ \mathrm{s} /$ ]. In Latin, the prothetic vowel before $/ \mathrm{s} /+\mathrm{C}$ thus could only be Ǐ (short /i/), which variously evolved into long /i/ or into /e/. In 11 th century old French, a prothetic vowel before /s/+C occurred only after a consonant (e.g., "il out espusethe" [he had married]), not after a vowel (e.g., "la spusa" [the spouse]). In 12th 
century old French, however, the prothetic vowel generalized, as well as in Iberian Romance languages. Later on, due to borrowings from old Latin, Germanic, and other languages, the systematicity of the prothetic vowel was lost in French, but not in languages such as Spanish.

${ }^{3}$ We implicitly suggest here that a prime can "pre-activate" a word target and that target processing can thereby be "facilitated," compared to a priming situation where that word would presumably not be pre-activated. This is a rather standard view of priming effects. Another view posits that masked priming is always a perturbation on target word perception (Van Orden, Holden, Podgornik, \& Aitchinson, 1999). Perturbation decreases, hence priming increases, when prime-target redundancy increases for the code currently computed (or "activated"). Both views, however, would predict increased priming (more pre-activation or less perturbation) with increased prime-target redundancy.

${ }^{4}$ A recent study by New, Ferrand, Pallier, and Brysbaert (2006), based on the English Lexicon Project data (Balota, Cortese, Hutchison, Neely, Nelson, Simpson, \& Treiman, 2002) indicates that the function relating lexical decision latency and word length, after other factors such as frequency, number of neighbors, etc., have been factored out, is U-shaped: for lengths of 3-5 letters, latencies decrease with length, for 8-12 letters, latencies increase with length, and they are stable for 5-8 letters.

${ }^{5}$ For the filler trials data, no advantage for correct over incorrect responses was found (48.2\% correct vs. $50.2 \%$ incorrect), $t \mathrm{~s}<1$. A signal detection analysis yielded d' not different from $0\left(\mathrm{~d}^{\prime}=-0.08, \mathrm{t}(25)<1\right)$ and $\beta$ not different from $1(\beta=1.07, \mathrm{t}(25)<1)$, hence no sign of discrimination or of decision bias.

${ }^{6}$ For the asC-targets, RTs were longer and error rate was lower in the partial than in the full repetition condition (Table 4). This pattern might reflect a speed-accuracy tradeoff. A speedaccuracy tradeoff would result in an overall negative correlation between RT and error-rate. 
However, within the asC- data, the correlation was actually positive for both the items and subjects data. If we nevertheless combine $\mathrm{RT}$ and error-rate, using the $\mathrm{RT} / p$ (correct) measure proposed by Townsend and Ashby (1983), a significant alteration effect for the asC- targets still obtains: 842 vs. 896 ms "corrected" RTs for full vs. partial repetition.

7 According to Alameda and Cuetos (1995), there are 401 "asC-" word types (whose pronunciation begins with $\mathrm{VsC}$ where $\mathrm{V} \neq / \mathrm{e} /$ ) among which 125 with and 256 without an initial ' $h$ '. In average, those with ' $h$ ' are more frequent than those without (39.1 vs. 11.9 o.p.m.). There are no esC- word with an initial ' $h$ ' in Spanish.

${ }^{8}$ The correlation was marginally significant for astuto targets in the partial repetition condition, $r(22)=0.38, p=.070$.

9 The regression equations relating RT to target length and to target frequency in each of the two priming conditions can be used to correct the mean RT for the ' $h$ '-initial targets to that for the other targets (in the items data). The corrections are $39 \mathrm{~ms}$ and $55 \mathrm{~ms}$ for the partial and full repetition condition, respectively; they account for $80.8 \%$ of the difference between targets with and without ' $h$ '.

10 There is some indication for intrinsically slower RTs to "especial" than to "astuto" targets. In Experiment 4, in the full repetition priming condition, RTs to "especial" are not faster than to "astuto" ( $862 \mathrm{~ms}$ vs. $848 \mathrm{~ms}$ ), although the former type of targets are shorter by one letter in average than the latter type. This is intriguing since RTs were consistently found to correlate positively with target length across the four experiments. In Experiment 3, in which "especial" and "astuto" targets have, in average, about the same length, RTs to "especial" are slower than to "astuto" in the full repetition priming condition (822 vs. $767 \mathrm{~ms}$ ). 
Table 1. Response times for the correct ('yes') responses (in ms) and error percentages (in parentheses) for the four categories of prime-target pairs in Experiment 1. The "alteration effect" is the RT difference between the partial and full repetition priming conditions.

Target type

initial V example full repetition

$\mathrm{V}=/ \mathrm{e} / \quad$ especial $941(6.3 \%)$

$\mathrm{V} \neq / \mathrm{e} /$

astuto

$948(3.7 \%)$
Priming type

partial repetition

$933(6.5 \%) \quad-8 \mathrm{~ms}$

$935(3.9 \%)$ alteration effect

$-13 \mathrm{~ms}$ 
Table 2. Percentages of correct vs. incorrect responses and of "different" vs. "same" responses for the test and filler trials of the prime visibility test of Experiment 2.

Target Type

example

esC- especial

asC- astuto

fillers pequeña

means
Response Type

$\begin{array}{llll}\text { correct } & \text { incorrect } & \text { different } & \text { same } \\ 51.9 & 46.6 & 52.9 & 45.7 \\ 51.6 & 47.3 & 53.2 & 45.7 \\ 48.2 & 50.2 & 44.1 & 54.4 \\ 50.0 & 48.6 & 48.6 & 50.0\end{array}$


Table 3. Response times (ms) and error percentages (in parentheses) for the four categories of prime-target pairs in Experiment 2; "alteration effect" as in Experiment 1 (cf. Table 1).

Target type initial V example $\mathrm{V}=/ \mathrm{e} /$ especial

$\mathrm{V} \neq / \mathrm{e} /$
Priming type

repetition

$782(14.1 \%)$

$762(8.4 \%)$ partial repetition

$801(11.8 \%) \quad 19 \mathrm{~ms}$

$808(9.3 \%)$ alteration effect

$46 \mathrm{~ms}$ 
Table 4. Response times (ms) and error percentages (in parentheses) for the four categories of prime-target pairs in Experiment 3; "alteration effect" as in Experiments 1-2 (cf. Table 1).

Target type initial V $\mathrm{V}=/ \mathrm{e} /$ especial

$\mathrm{V} \neq / \mathrm{e} /$
Priming type

partial repetition

full repetition

$822(10.0 \%)$

$767(7.6 \%)$
$801(7.9 \%)$

822 (6.9\%) alteration effect

$-21 \mathrm{~ms}$

$56 \mathrm{~ms}$ 
Table 5. Response times (ms) and error percentages (in parentheses) for the six categories of prime-target pairs in Experiment 4; "alteration effect" as in Experiments 1-3 (cf. Table 1).

Target type initial V word type example $\mathrm{V}=/ \mathrm{e} /$

$\mathrm{V} \neq / \mathrm{e} / \quad$ asCesC-

especial

(n)

Priming type

alteration effect

('h'-initial) histeria

$817(6.1 \%)$

$857(6.9 \%)$

full repetition partial repetition

$862(5.4 \%)$

$837(7.3 \%)$

$-25 \mathrm{~ms}$

$848(6.1 \%)$

$887(9.8 \%)$

$+39 \mathrm{~ms}$

$$
\text { (no 'h') astuto }
$$

$837(4.9 \%)$

$+20 \mathrm{~ms}$

$899(11.4 \%) \quad+42 \mathrm{~ms}$ 


\section{Figure caption}

Figure 1. Alteration effect in the four experiments. Experiments 1-3: prime onset to target onset SOA of 44, 88, and $132 \mathrm{~ms}$; empty circles (O) for "astuto", black diamonds $(\bullet)$ for "especial" targets. Experiment 4: $132 \mathrm{~ms}$ SOA; grey circle and diamond symbols for "astuto" and "especial" targets, respectively. 
Figure 1

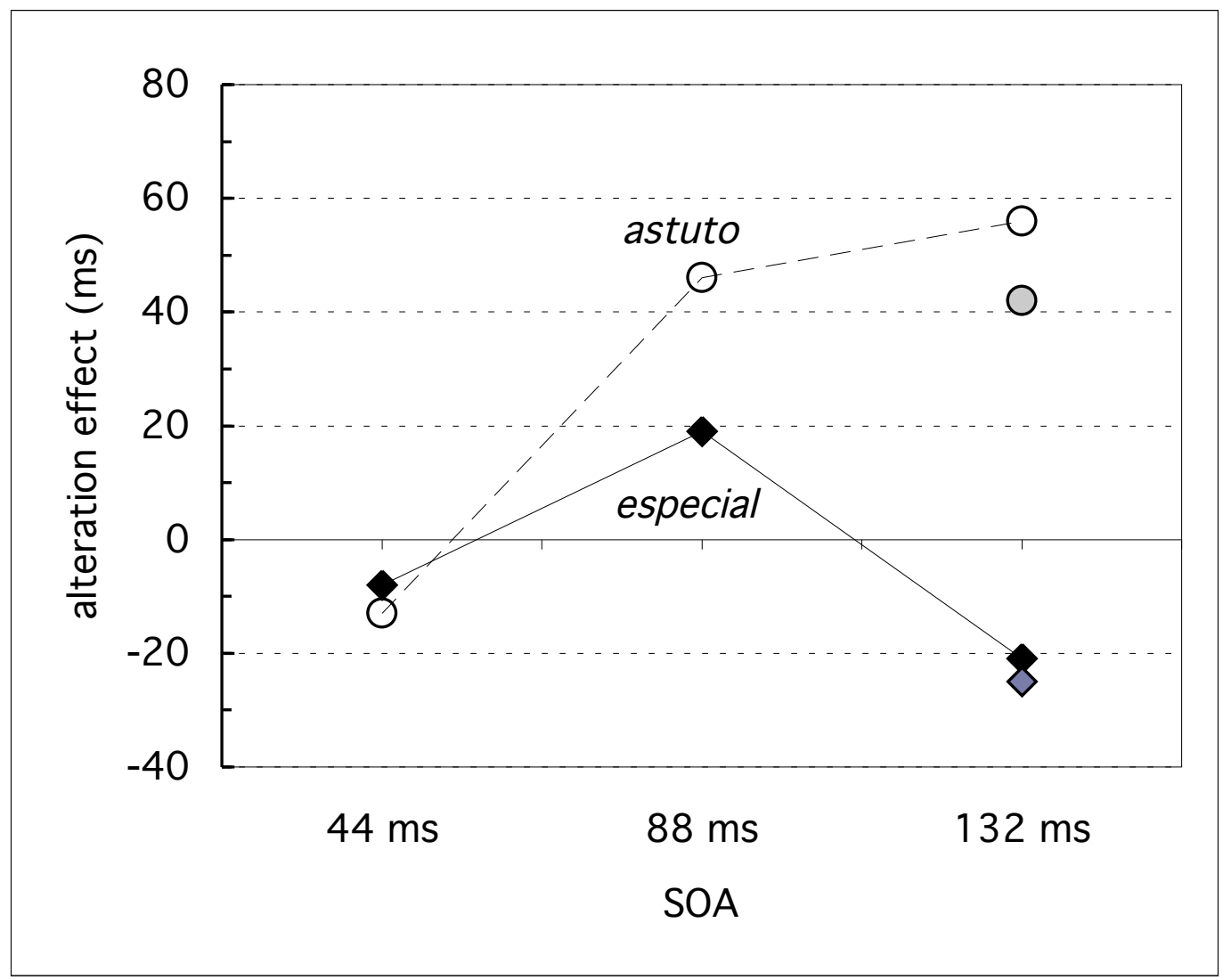

